Results: A total of 2847 publications were retrieved, including 2636 articles and reviews. Before 2000, there were only 15 relevant papers, which were not included in the specific analysis. It is clear that the number of publications on PRP related OA study is increasing every year, a total of 398 articles or reviews were published in 2020 . The United States is the leading country in this field, with a number of 932 publications (35.4\%), followed by Italy (304 publications, $11.5 \%$ ) and China (294 publications, $11.2 \%$ ). The most prevalent areas of PRP related OA research were orthopedics (1013 papers, 38.4\%), sports science (651 papers, $24.7 \%$ ) and surgery (475 papers, $18.0 \%$ ). The top 3 journal that published the most PRP related OA study is American Journal of Sports Medicine (153 papers, 5.8\%), Arthroscopy: The Journal of Arthroscopic \& Related Surgery (95 papers, 3.6\%), Journal of Orthopaedic Research (83 papers, 3.1\%). The Harvard University (96 papers, 3.6\%), Hospital for Special Surgery (83 papers, $3.1 \%$ ) and University of London (75 papers, $2.8 \%$ ) is the top 3 institution that published the most articles or reviews. Filardo $\mathrm{G}$ from Italy published the most articles or reviews $(52,2.0 \%)$ in this area, followed by Maffulli $\mathrm{N}$ from the UK (49 publications, $1.9 \%$ ) and Kon $\mathrm{E}$ from Italy (46, 1.7\%). PRP related OA study can be divided into five categories: intra-articular treatment study, clinical trials related study, soft tissue repairment study, gene and molecular biology study, regeneration and implantation study.

Conclusion: Publications on PRP related OA study is increasing according to the analysis on current global trends. The United States is now the leading country in this field, with the largest number and the highest quality of publications. Among the five cluster of PRP related OA studies, "intra-articular treatment study" and "regeneration and implantation study" are considered to be the current research hotspots in the PRP related OA field.

REFERENCES:

[1] Foster T E, Puskas B L, Mandelbaum B R, et al. Platelet-rich plasma: from basic science to clinical applications.[J]. American Journal of Sports Medicine, 2009, 37(11):2259-2272.
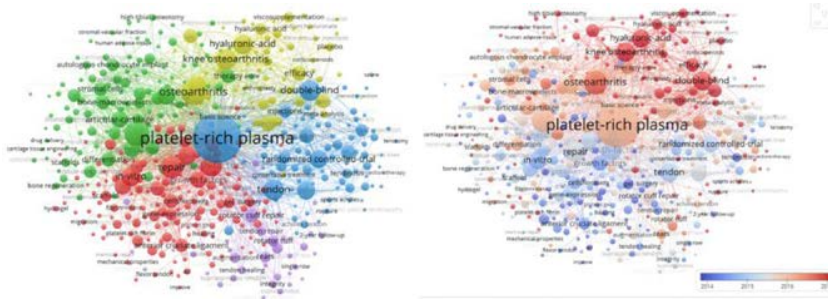

Disclosure of Interests: None declared

DOI: 10.1136/annrheumdis-2021-eular.2849

\section{AB0871-HPR WOMEN IN RHEUMATOLOGY: BARRIERS, LIMITATIONS, AND GENDER INEQUALITY}

G. Serna-Peña ${ }^{1}$, I. J. Colunga-Pedraza ${ }^{1}$, D. Á. Galarza-Delgado ${ }^{1}$, N. GuajardoJauregui ${ }^{1}$, D. Alpizar-Rodriguez ${ }^{2}$, C. F. Pacheco Tena ${ }^{2} .{ }^{1}$ Hospital Universitario

“Dr. José Eleuterio González", Universidad Autónoma de Nuevo León, Rheumatology, Monterrey, Mexico; ${ }^{2}$ Colegio Mexicano de Reumatología, Rheumatology, Ciudad de México, Mexico

Background: In the last decades there has been a great progress towards gender equality in medicine, and this can be reflected in the proportion of women in Rheumatology, which has been on the rise recently. However, there continues to be a need for women to be able to succeed on equal opportunities with men (1)

Objectives: The aim of this study was to recognize the professional limitations and barriers that Mexican female rheumatologists must face.

Methods: Female rheumatologists were invited to participate. An online survey was applied anonymously, consisting of questions regarding demographic characteristics, professional, academic and research activities, as well as perceptions of gender discrimination and limitations of their profession.

Results: A total of 127 female rheumatologists voluntarily answered the electronic survey. Most of them were aged between 30 and 35 years $(40.9 \%)$ and had $1-5$ years of professional practice $(40.2 \%$ ) (Table 1 ); $52 \%$ have children and $42.4 \%$ of them consider that motherhood has had a negative impact on their professional life; $75.6 \%$ of female rheumatologists do not work on research activities and only $20.5 \%$ have participated in international congresses in the last 5 years; $80.5 \%$ report not participating in medical colleges (as leaders or board members). The three main reasons female rheumatologists refer as limitations on their profession are: having other priorities $(34.6 \%)$, lack of time $(32.3 \%)$ and lack of support from their peers/bosses $(23.6 \%)$. Almost half women $(45.7 \%)$ consider not being discriminated because of their gender in their profession, while the rest of them consider that they are or may be.
Table 1. Demographic characteristics.

\begin{tabular}{ll}
\hline Age, $\mathbf{n}(\%)$ & \\
\hline Younger than 35 years & $52(40.9 \%)$ \\
From 35 to 40 years & $29(22.8 \%)$ \\
From 40 to 45 years & $16(12.6 \%)$ \\
From 45 to 50 years & $12(9.4 \%)$ \\
Older than 50 years & $18(14.2 \%)$ \\
Marital status, $\mathbf{n}(\%)$ & \\
Married & $66(52 \%)$ \\
Single & $38(29.9 \%)$ \\
Free union & $13(10.2 \%)$ \\
Divorced & $8(6.3 \%)$ \\
Widowed & $2(1.6 \%)$ \\
Years of professional practice, $\mathbf{n}(\%)$ & \\
From 1 to 5 years & $51(40.2 \%)$ \\
From 5 to 10 years & $31(24.4 \%)$ \\
From 10 to 15 years & $16(12.6 \%)$ \\
From 15 to 20 years & $10(7.9 \%)$ \\
More than 20 years & $19(15 \%)$ \\
\hline
\end{tabular}

Conclusion: We found that most female rheumatologists are young and with a few years of professional practice, which coincides with the recent increase in the proportion of women in Rheumatology; and perhaps this is the reason why there is low participation in research activities and medical colleges. It is relevant that almost half of them perceive their gender as a reason of discrimination in their professional life. We consider that initiating the conversation of gender equality in Rheumatology, in national and international forums, and to actively search for a strategy to support and encourage our colleagues, are priorities at this moment. REFERENCES:

[1] Andreoli L, Ovseiko PV, Hassan N, et al. Gender equity in clinical practice, research and training: Where do we stand in rheumatology? Joint Bone Spine 2019;86(6):669-72. doi: 10.1016/j.jbspin.2019.05.005.

[2] Colunga-Pedraza IJ, Arvizu-Rivera RI, Serna-Pena G, et al. Women's journey in Mexican rheumatology. Comment on 'Gender gap in rheumatology: speaker representation at annual conferences' by Monga et al. Ann Rheum Dis 2020 doi: 10.1136/annrheumdis-2020-218541.

Acknowledgements: We have no acknowledgements to declare.

Disclosure of Interests: None declared

DOI: 10.1136/annrheumdis-2021-eular.3429

\section{HPR Interventions (educational, physical, social and psychological)}

\section{AB0872-HPR IMPACT OF COVID-19 ON A PHYSICAL ACTIVITY FEASIBILITY PILOT STUDY:THE PIPPRA EXPERIENCE}

L. Larkin ${ }^{1}$, A. Moses ${ }^{1}$, S. Gallagher ${ }^{2}$, A. Fraser ${ }^{3,4}$, B. A. Esbensen ${ }^{5,6}$, J. Green ${ }^{1}$ L. Glynn ${ }^{7}$, N. Kennedy ${ }^{1} .{ }^{1}$ University of Limerick, School of Allied Health and Health Research Institute, Limerick, Ireland; ${ }^{2}$ University of Limerick, Department of Psychology and Health Research Institute, Limerick, Ireland; ${ }^{3}$ University of Limerick, School of Medicine, Limerick, Ireland; ${ }^{4}$ University Hospitals Limerick, Department of Rheumatology, Limerick, Ireland; ${ }^{5}$ Rigshospitalet, Center for Rheumatology and Spine Diseases, Copenhagen, Denmark; ${ }^{6}$ University of Copenhagen, Department of Clinical Medicine, Copenhagen, Denmark; ${ }^{7}$ University of Limerick, School of Medicine and Health Research Institute, Limerick, Ireland

Background: The PIPPRA (Physiotherapist-led Intervention to Promote Physical Activity in Rheumatoid Arthritis) project is a feasibility project examining the impact of a physical activity behaviour change intervention in people who have rheumatoid arthritis (RA). The PIPPRA study recruitment commenced in October 2019, with participant assessment and intervention commencing in Novembe 2019. In the Republic of Ireland people who have RA are categorised as high risk category for Covid-19, due to immunosuppression [1], although this categorisation contrasts with EULAR's provisional recommendations [2]

Objectives: To examine the impact of the Covid-19 pandemic and public health restrictions on a pilot randomised controlled feasibility study in 2020 .

Methods: Participants (aged 18 years+, diagnosis of RA, independently mobile and low levels of physical activity [3]) were recruited from a rheumatology clinic at an urban hospital. Target recruitment was four participants per month for one year $(\mathrm{N}=48)$. Assessments were planned at baseline, eight and twenty-four weeks $(\mathrm{N}=144)$. Participants were randomised to intervention group or control group. The intervention group received four 1:1 sixty minute sessions with physiotherapist $(\mathrm{N}=96)$. The intervention was delivered over eight weeks. Intervention and control groups received a physical activity information leaflet. Results: The Covid-19 pandemic and associated public health restrictions forced the study to be formally paused in April 2020 and the study formally resumed 